\title{
Application of Genetic Neural Network for Diagnosis of Anode Anomaly and Metal Wave in Aluminum Electrolysis
}

\author{
Shuiping Zeng and Bing Liu \\ College of electrical and control engineering, North China University of Technology, Beijing
}

\begin{abstract}
This paper presents a neural network model based on the cell resistance signal. In the model, the anode current spectral energy is set as the input vector; the normal production, anode anomaly and metal wave are set as the output sample. By using genetic algorithm to optimize the initial weights and thresholds of the network, the model realized the diagnosis of the anode anomaly and metal wave in the production of aluminum electrolysis. The results show that the non-optimized neutral network needs to be trained 3131 times to achieve the specified precision and running time is 388s. Then the one optimized by genetic algorithm needs to be trained 2571 times to achieve the specified precision and running time is 222s. The results of the diagnosis system applied to the $350 \mathrm{kA}$ aluminum electrolysis

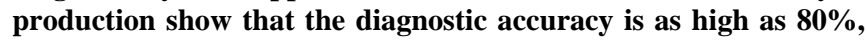
basically meet the needs of the production process.
\end{abstract}

Keywords-neutral network; genetic algorithm; aluminum electrolysis; fault diagnosis component

\section{INTRODUCTION}

The running state detection and fault diagnosis of aluminum cells is an important part in aluminum electrolysis industry, and is also a bottleneck during improving the automation level in aluminum electrolytic industry. The aluminum cell is a nonlinear, multivariable coupling, timevarying and large time-delay industrial process system. In the aluminum electrolysis process, the changing material balance and energy balance status are influenced and restrained with each other, then formed complex and changeable cell conditions, such as the anode effect, the anode lesion, cool electro bath, hot electrobath and unstable electrobath. There are many fault types, once some of them occurs, it will cause a great deal of economic loss and affect the safety in production process[1]. It is becoming an urgent topic to forecast the fault in advance during the electrolytic process, reduce the economic loss, improve the yield and quality of aluminum, reduce the energy consumption of the electrolytic aluminum, and improve the service life of aluminum electrolytic cell.

The intelligent diagnosis of the aluminum electrolytic cell has made a great progress both in theory and in system development[2-3]. Oakland University developed a new type of aluminum reduction cell control system with the on-line monitoring of the cell condition[4]. Tsinghua University has developed a fault diagnosis and predictive maintenance system of typical process industry equipment, which included health diagnosis of aluminum electrolytic cell[5]. Central South
University studied the diagnosis system about information element of noises of aluminum electrolytic cells based on wavelet packet transform pretreatment[6]. However, it is hard to get perfectly functional and universally applicable systems due to the complex environment of the aluminum electrolysis process, and most of the study results are still in the experimental stage.

\section{Aluminum Electrolytic Process}

Aluminum electrolysis is a complex industry process which is using alumina as raw materials, molten cryolite as solvent, carbon materials as anode, the aluminum liquid of carbon lining as cathode. Electrolyzing molten alumina produces carbon dioxide and carbon monoxide at the anode and the metal cathode at the cathode. The chemical equation is as below:

$$
2 \mathrm{Al}_{2} \mathrm{O}_{3}+3 \mathrm{C}=4 \mathrm{Al}+3 \mathrm{CO}_{2}
$$

Aluminum electrolytic cell is a nonlinear, multivariable coupling, time-varying and large time-delay industrial process system which always works in heavy current, high temperature and highly erodent melt conditions. Due to subjecting to the electromagnetic force, gas and other effect simultaneously, many of the parameters and variables are uncertain and can't be continuous measured online, so that the important parameters of aluminum cells (alumina concentration, bath temperature in aluminum electrolysis) cannot be measured online. Only the cell voltage and current can be collected online at present, however, the cell resistance which can respond the cell condition real-timely cannot be measured online can only be obtained via the cell voltage and current. Besides cell resistance, the other parameters also can't be measured online, so we can't establish the complete mathematical model[7].

In the aluminum electrolysis process, the changing material balance and energy balance status are influenced and restrained with each other, then formed complex and changeable cells conditions. The main fault of the aluminum cells is anode anomaly and metal wave. Anode anomaly include: Anodic effect, anode lesions, and anodic bract, which is mainly due to such factors as poor quality of the anode, cool electrobath, hot electrobath and unstable electrobath; Level fluctuation of liquid aluminum is mainly caused by the 
irregular cell, anode current unbalance, the factors can cause magnetic field and melt flow disorders in the cells.

\section{StRUCTURE OF BP NEURAL NETWORK}

\section{A. Choice of Input-output Parameter}

Reference 8 studied and collected the resistance signal of aluminum cells in the normal condition and abnormal condition of 350kA aluminum electrolysis cells[8]. Through the signal spectrum analysis, we found that the frequency and spectrum of resistance signal are different between each cell condition, which is normal, level fluctuation of aluminum liquid and anode anomaly. The characteristics of different cell conditions in the aluminum electrolysis are shown in Table 1.

TABLE I. CHARACTERISTICS OF DIFFERENT CELL CONDITIONS

\begin{tabular}{|c|c|c|c|c|}
\hline \multirow[b]{2}{*}{$\begin{array}{c}\text { Cell } \\
\text { condition }\end{array}$} & \multicolumn{4}{|c|}{ Characteristic } \\
\hline & $\begin{array}{c}\text { Frequency } \\
\text { spectrum } \\
\text { energy }\end{array}$ & $\begin{array}{c}\text { In the lower } \\
\text { frequency(below } \\
0.01 \mathrm{~Hz})\end{array}$ & $\begin{array}{l}\text { In the mid- } \\
\text { frequency } \\
(0.01 \sim 0.1 \mathrm{~Hz})\end{array}$ & $\begin{array}{c}\text { In the high } \\
\text { frequency (abov } \\
\text { e } 0.1 \mathrm{~Hz})\end{array}$ \\
\hline normal & Low & $\begin{array}{c}\text { Has a control } \\
\text { signal }\end{array}$ & $\begin{array}{l}\text { No clear } \\
\text { regularity }\end{array}$ & $\begin{array}{c}\text { No obvious } \\
\text { peak }\end{array}$ \\
\hline $\begin{array}{l}\text { metal } \\
\text { wave }\end{array}$ & Higher & $\begin{array}{l}\text { Has a control } \\
\text { signal }\end{array}$ & $\begin{array}{c}\text { One obvious } \\
\text { peak at } \\
0.02 \sim 0.03 \mathrm{~Hz}\end{array}$ & $\begin{array}{c}\text { No obvious } \\
\text { peak }\end{array}$ \\
\hline $\begin{array}{c}\text { anode } \\
\text { anomaly }\end{array}$ & higher & $\begin{array}{c}\text { Has a control } \\
\text { signal }\end{array}$ & $\begin{array}{c}\text { Two } \\
\text { obvious } \\
\text { peaks at } \\
0.03 \sim 0.04 \mathrm{~Hz} \\
\text { and } \\
0.06 \sim 0.07 \mathrm{~Hz}\end{array}$ & $\begin{array}{c}\text { No obvious } \\
\text { peak }\end{array}$ \\
\hline
\end{tabular}

Therefore, the fault sample and network model based on the spectrum energy is established. The input vector P0, P1, P2, P3, P4, P5, P6, P7, P8, P9 represent the total energy between $0 \sim 0.01 \mathrm{~Hz}, \quad 0.01 \sim 0.02 \mathrm{~Hz}, \quad 0.02 \sim 0.03 \mathrm{~Hz}, \quad 0.03 \sim 0.04 \mathrm{~Hz}$, $0.04 \sim 0.05 \mathrm{~Hz}, \quad 0.05 \sim 0.06 \mathrm{~Hz}, \quad 0.06 \sim 0.07 \mathrm{~Hz}, \quad 0.07 \sim 0.08 \mathrm{~Hz}$, $0.08 \sim 0.09 \mathrm{~Hz}$ respectively.

Output vector includes 3 modes, which is expressed in the following form: Normal Y1 :( $\left.\begin{array}{lll}1 & 0 & 0\end{array}\right)$; Metal wave Y2 (l0 0 1); anode anomaly Y3: $\left(\begin{array}{lll}0 & 1 & 0\end{array}\right)$.

\section{B. Determination of the Input Layer and Output Layer Node Number}

The number of the input layer is determined by the dimension of the input vector, the dimension of the input vector is 10 .

The number of neurons in the output layer is determined by different kinds of cell conditions. The cell conditions of the aluminum reduction cell are three modes, so 3 is the number of neurons in the output layer.

\section{Choice of the Hidden Layer Nodes}

The following empirical formula is used to determine the node number of hidden layer in the three layers BP network.

$$
h \geq \sqrt{n+m}+a
$$

where, $\mathrm{h}$ is node number of hidden layer. $\mathrm{n}$ is the number of neurons in the input layer. $m$ is the number of neurons in the output layer. a is constant between $1 \sim 10$.

Let $\mathrm{h}=10, \mathrm{~m}=3, \mathrm{a}=4$. According to the Formula (2.2), $h \geq \sqrt{10+3}+4$, we get $h \geq 7.6$.Finally, the node number of the hidden layer is 8 .

\section{Choice of Learning Parameters}

Take the learning rate is 0.08 and the expected error is 0.005 after repeating experiment and simulation.

\section{E. Structure of the Neural Network}

BP neural network has 10 input neurons, 3 output neurons, 8 neurons in the hidden layer. Suppose BP neural network composes by input layer (I), hidden layer $(\mathrm{H})$ and output layer (O), let $I_{i}$ be the i-th neurons output vector of input layer, $H_{j}$ be the j-th neurons output vector of hidden layer, $O_{k}$ be the k-th neurons output vector of output layer. Let $W I H_{i j}$ be the connection weights between the i-th neurons in the input layer and the j-th neurons in the hidden layer, $W H O_{j k}$ be the connection weights between the j-th neurons in the input layer and the k-th neurons in the hidden layer. $h_{j}$ is the j-th neurons threshold of hidden layer. $O_{k}$ is the k-th neurons threshold of output layer, where $1 \leq i \leq 10,1 \leq j \leq 8,1 \leq k \leq 3$.

The three layers BP neural network topology is shown in Figure 1.

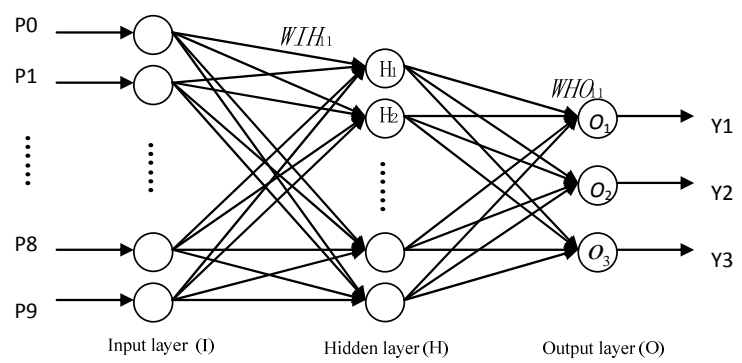

FIGURE I. TRAINING ALGORITHM OF BP NEURAL NETWORK

\section{F. Training Algorithm of BP Neural Network}

Let $\varepsilon_{B P}=0.005$ ( $\varepsilon_{B P}$ represent the expected error), the learning rate be 0.08 and maximum training number be 5000 . The transfer functions of the input layer to the hidden layer and the hidden layer to the output layer are Tansig and logsig. Take BP neural network algorithm to train the network, after 3131 times training, BP neural network can achieve the specified precision, and the running time is 388.28s.

$\mathrm{BP}$ network training process curve of training function is shown in Figure 2. 


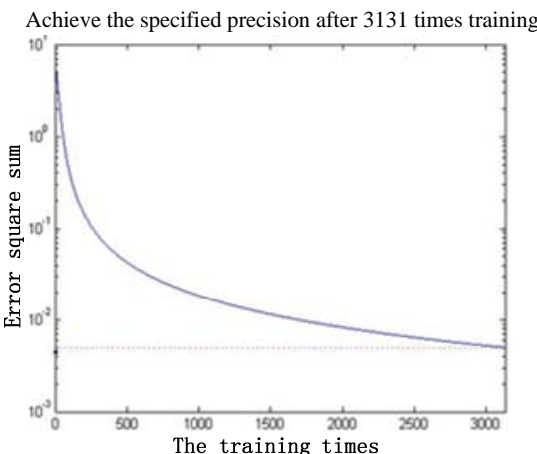

FIGURE II. BP NETWORK TRAINING PROCESS CURVE

\section{Genetic AlgORITHM Optimized BP NEURAL NETWORK}

Genetic algorithm is used to optimize the initial value, and the initial value will be showed as the initial weights and threshold of the neural network, then training the network with $\mathrm{BP}$ algorithm until achieving the specified precision which is $\varepsilon_{B P}=0.005$. The activation functions of input layer to the hidden layer and hidden layer to the output layer are Tansig and logsig.

The flow chart of the genetic algorithm is shown in Figure 3.

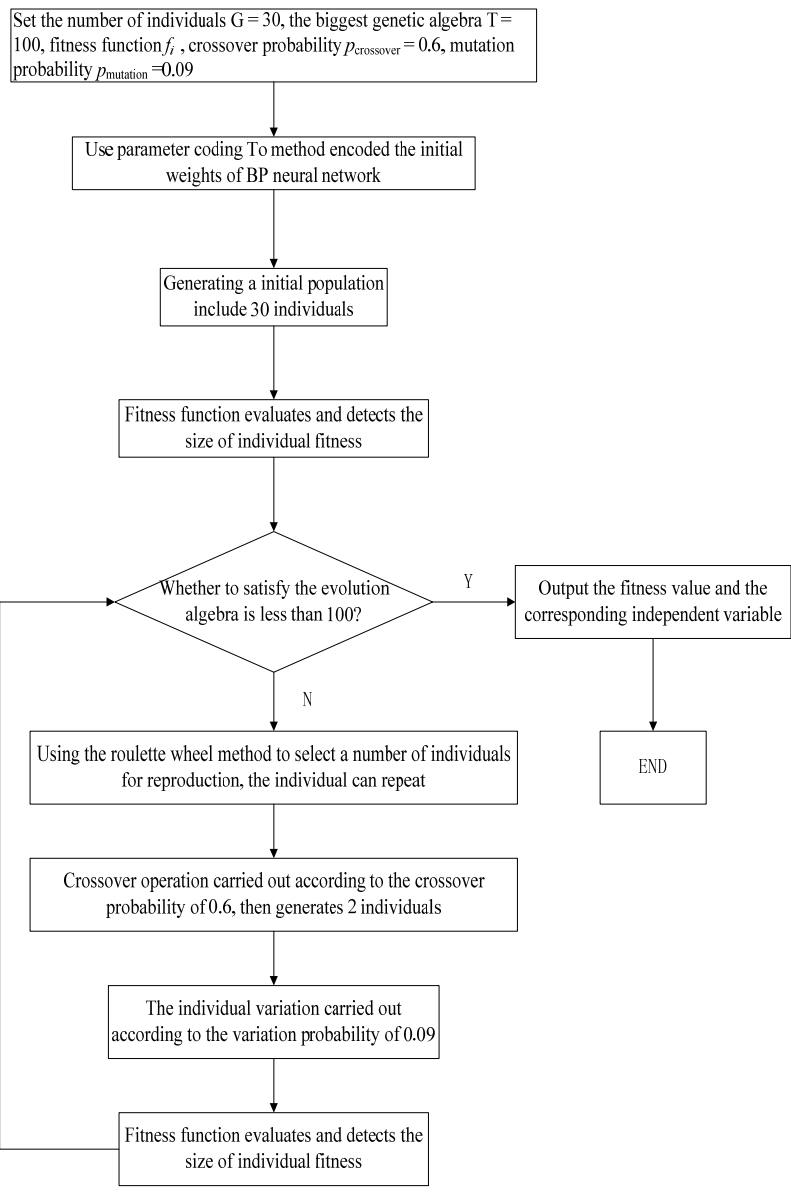

FIGURE III. FLOW DIAGRAM OF GENETIC ALGORITHM
Genetic algorithm is used to optimize the weights and thresholds of neural network. The neural network is studying through BP algorithm. After 2571 times training, the neural network achieves the specified precision and the running time is 222.00s. After 80 generations of genetic operations, the network achieves the specified target, that is $\varepsilon_{G A}=5.0$. The curve of training target is show in Figure 4.

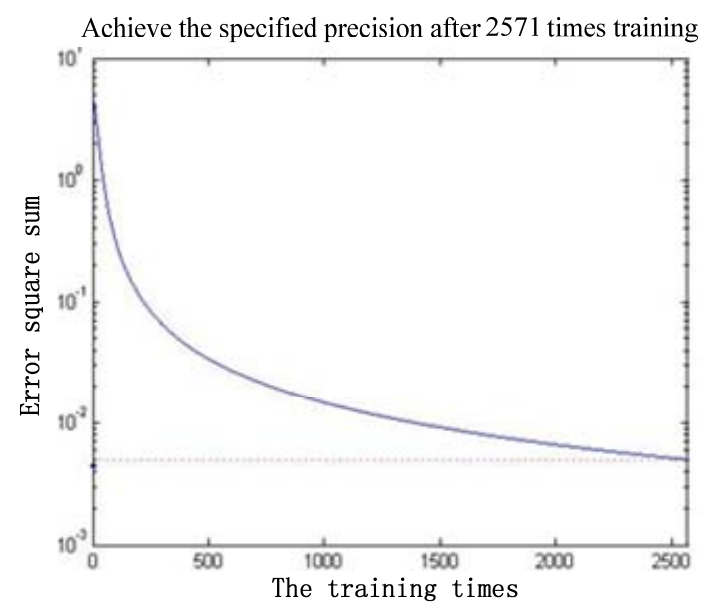

FIGURE IV. TARGET CURVE OF THE GA-BP NEURAL NETWORK TRAINING

\section{VAlidation of Diagnostic Models}

Take 30 groups of data as the test sample to test the BP network. The results show that 24 groups of data in the 30 groups can diagnose the cause of fault accurately, that is the correct rate reached $80 \%$. So the fault diagnostic model meets the requirements of industrial production.

\section{REAlization Of Diagnostic SyStem}

System interface is shown in Figure 5 , it can realize the date management: real-time display of aluminum cell's condition, dynamic curve display, print, etc. The fault prediction and diagnosis of the aluminum cell is realized.

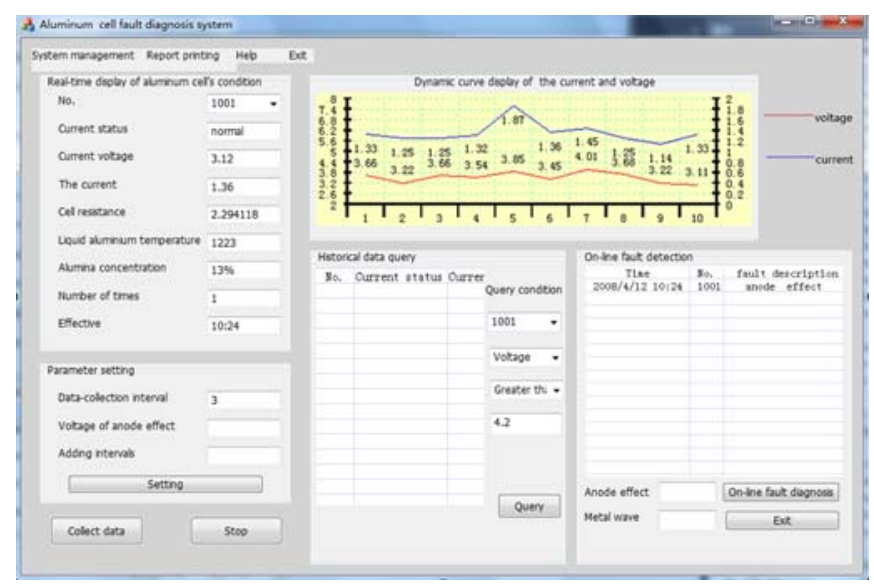

FIGURE V. THE SYSTEM MAIN INTERFACE 


\section{CONCLUSION}

In this paper, neural network was used to diagnose the cell conditions, the initial weights and threshold of BP neural network was optimized by genetic algorithm, the running time reduced by $50 \%$ eventually. The results of the diagnosis system applied to the $350 \mathrm{kA}$ aluminum electrolysis production show that the diagnostic accuracy is as high as $80 \%$, basically meet the needs of the production process. Through the MATLAB programming, the diagnostic system realizes the real-time display of date and dynamic curve display, report generation and printing. Due to the complex and volatile industrial production environment and process, the system remains to be further tested in aluminum production process.

\section{ACKNOWLEDGMENT}

This work is supported by National Natural Science Foundation of China (Project 51174007).

First of all, I would like to extend my sincere gratitude to my supervisor, Zeng Shuiping, for his instructive advice and useful suggestions on my thesis. I am deeply grateful of her help in the completion of this thesis.

I am also deeply indebted to all the other tutors and teachers in Translation Studies for their direct and indirect help to me.

Finally, I am indebted to my parents for their continuous support and encouragement.

\section{REFERENCES}

[1] Yexiang Liu, Jie Li, Modern Aluminum Electrolysis, 1st. ed. China: Metallurgical Industry Press, 2008.

[2] Shuiping Zeng, Lin Cui and Jinhong Li. "Diagnosis System for Alumina Reduction Based on BP Neural Network, ” Journal of Computers, vol.7. No. 4. pp. 929-933, 2012.

[3] Cheung, Cheuk-Yi; Menictas, Chris; Bao, Jie, "Characterization of individual anode current signals in aluminum reduction cells.” Industrial and Engineering Chemistry Research. vol.52. No.28, pp.9632-9644, July 17, 2013.

[4] Mulder, Albert; Gao, Yashuang; Zhou, Dongfang, "New generation control for daily aluminium smelter improvement generation 3 process control for potlines,” Light Metals 2014-At the TMS 2014 Annual Meeting and Exhibition , pp. 835-840, 2014.

[5] Minhua Liu, Deyun Xiao, "Fault Diagnosis Method Based on SDG Model and Fuzzy Fusion." Control Engineering of China. vol.13. pp.1014. January 2006.

[6] Hesong Li, Zhi Mei, Yongbo Huang, "Analysis and diagnosis of information elements of noise in aluminum reduction cells based on wavelet packet preconditioning,” Light Metals. vol. 2. pp.36-39, 2006.

[7] A.I.Berezin, P.V.Poliakov, O.O.Rodnov. "Neural network qualifier of noises of aluminum reduction cell,” Light Metals, pp. 437-440, 2003

[8] Zeng Shuiping, Ding Lei,"Frequency characteristic and its application of the cell resistance in aluminum electrolysis,"ICCSE 2012- Proceedings of 2012 7th International Conference on Computer Science and Education, pp. 165-168, 2012. 